\title{
The association between CCR5 $\Delta 32$ polymorphism and susceptibility to breast cancer
}

\author{
Junlong Li ${ }^{1, *}$, Yuan Peng ${ }^{2, *}$, Hui Liu ${ }^{3}$ and Qiang Wu ${ }^{1}$ \\ ${ }^{1}$ Department of Medicine and Teaching, Southwest Hospital, Third Military Medical University, Chongqing 400038, China \\ ${ }^{2}$ Department of Oncology, Southwest Hospital, Third Military Medical University, Chongqing 400038, China \\ ${ }^{3}$ Department of Hepatobiliary Surgery, Southwest Hospital, Third Military Medical University, Chongqing 400038, China \\ *These authors have contributed equally to this work \\ Correspondence to: Qiang Wu, email: yukilin@126.com \\ Keywords: CCR5, polymorphism, breast cancer, susceptibility, meta-analysis \\ Received: October 27, $2016 \quad$ Accepted: March 09, $2017 \quad$ Published: August 05, 2017 \\ Copyright: Li et al. This is an open-access article distributed under the terms of the Creative Commons Attribution License 3.0 \\ (CC BY 3.0), which permits unrestricted use, distribution, and reproduction in any medium, provided the original author and source \\ are credited.
}

\section{ABSTRACT}

Background: Chemokine C-C motif receptor 5 (CCR5) gene polymorphisms have been proposed to play important roles in tumors. $\Delta 32$ polymorphism of this gene might correlate with breast cancer (BC) susceptibility. Nevertheless, inconsistent conclusions have been achieved as yet. We carried out this meta-analysis to draw a more comprehensive and convincing conclusion on this issue.

Results: No significant correlation of CCR5 $\Delta 32$ polymorphism with individual susceptibility to $B C$ was detected in either total analysis ( $\Delta 32$ vs. WT: $O R=1.12$, $95 \% \mathrm{CI}=0.76-1.65 ; \mathrm{WT} / \Delta 32$ vs. $\mathrm{WT} / \mathrm{WT}$ : $\mathrm{OR}=1.21,95 \% \mathrm{CI}=0.81-1.80$ ) or subgroup analyses by ethnicity and control source.

Methods: All eligible studies were searched from electronic databases including Chinese National Knowledge Infrastructure (CNKI), PubMed, EMBASE, and Google Scholar Web. Strength of association between CCR5 $\triangle 32$ polymorphism and BC susceptibility was evaluated using pooled odds ratios (ORs) with their corresponding $95 \%$ confidence intervals (95\% CIs). To further detect their correlation in specific populations, subgroup analyses were performed based on ethnicity and control source. Sensitivity analysis was conducted in this meta-analysis to test statistical stability of the final results. Publication bias among included studies was inspected with Begg's funnel plot and Egger's test.

Conclusion: CCR5 $\Delta 32$ polymorphism may not independently affect the risk of BC.

\section{INTRODUCTION}

Breast cancer $(\mathrm{BC})$ is the most frequently diagnosed malignancy among women around the world, and its incidence rate has been increasing globally, especially in developed countries compared with developing ones $[1,2]$. With the advancements in medical techniques, the mortality rate of this cancer shows a downward trend in the past few decades [3], though its morbidity sees no decline [4]. As a leading cause of cancer-related deaths in females [5], BC has higher morbidity and mortality in the worldwide in recent years [6]. According to corresponding statistics, about $50 \%$ of the new BC cases and $60 \%$ of
BC-related deaths occur in less developed countries and regions, and the incidence age of such cancer shows an increasing tendency in younger women [7]. Both genetic and epigenetic factors are reported to be involved in the etiology of this complex and multi-factorial disease [8]. Epidemiological studies have also shown that female reproductive status plays vital roles in the initiation of $\mathrm{BC}$ [9]. However, among women facing same risk factors for $\mathrm{BC}$, only a small part finally develop this cancer, and familial history of such malignancy is reported to contribute to approximately $5 \%$ to $10 \%$ of all BC cases [10], which indicates the significant functions of genetic factors in $\mathrm{BC}$ onset [11]. 
Chemokines are a class of small cytokines which could be categorized into four subfamilies, namely the $\mathrm{CXC}, \mathrm{CC}, \mathrm{C}$ and $\mathrm{CX} 3 \mathrm{C}$ chemokines. Chemokines take part in immune cell trafficking during inflammatory responses through interacting with chemokine receptors on the surface of immune cells $[12,13]$. As a member of the CC chemokine receptor group, chemokine $\mathrm{C}-\mathrm{C}$ motif receptor 5 (CCR5) can regulate the trafficking and effector functions of memory/effector T cells, macrophages, immature dendritic cells and natural killer cells [14]. This receptor binds to the chemokines MIP-1 $\alpha$ (CCL3), MIP-1 $\beta$ (CCL4), and RANTES (CCL5), and exerts its functions through $\mathrm{G}$ protein [15]. In addition, CCR5 also plays a pivotal role in cancer progression via recruiting immune cells [16]. In CCR5 gene, some polymorphisms have been identified, and among them, the $\Delta 32$ polymorphism has been reported to affect the severity of multiple autoimmune and infectious diseases through mediating inflammatory responses [17].

The influence of $C C R 5 \Delta 32$ polymorphism on BC susceptibility has been explored in previous studies among different populations, but the number of these researches was relatively small. We therefore performed this metaanalysis to more systematically explore this issue.

\section{RESULTS}

\section{Study characteristics}

Literature search strategy initially identified 97 potentially relevant publications from the databases, and 4 of them were firstly removed for being duplicates (Figure 1). During further screening, 87 more papers were excluded for irrelevance with $\mathrm{BC}$ (26) or CCR5
$\Delta 32$ polymorphism (41), being summaries or letters (6) or genome wide association studies (5), without a casecontrol design (3) or having usable data (6). Ultimately, a total of 6 eligible studies recruiting 1839 participants were incorporated into the present meta-analysis [18-23]. Among them, 3 were carried out among Caucasians, 2 were among Asians and 1 was among Brazilians. Table 1 describes the major characteristics of all included studies.

\section{Data synthesis}

As shown in Table 2, CCR5 $\triangle 32$ polymorphism showed no correlation with the risk of $\mathrm{BC}$ under the genetic models of $\Delta 32 \mathrm{vs}$. WT and WT/ $\Delta 32 \mathrm{vs}$. WT/WT $(\mathrm{OR}=1.12,95 \% \mathrm{CI}=0.76-1.65 ; \mathrm{OR}=1.21,95 \% \mathrm{CI}=0.81-$ 1.80 (Figure 2)). After stratification analyses by ethnicity and source of control, a similar trend was also revealed in Asian, Caucasian, Brazilian, hospital-based and population-based subgroups.

\section{Heterogeneity test}

$\mathrm{Q}$ test revealed no significant heterogeneity among included studies $(P>0.05)$, so the fixed-effects model was employed for ORs calculation.

\section{Sensitivity analysis}

The deletion of any one of the included studies did not alter summary ORs qualitatively during the whole process of sensitivity analysis (data not shown), confirming the statistical stability and robustness of our findings.

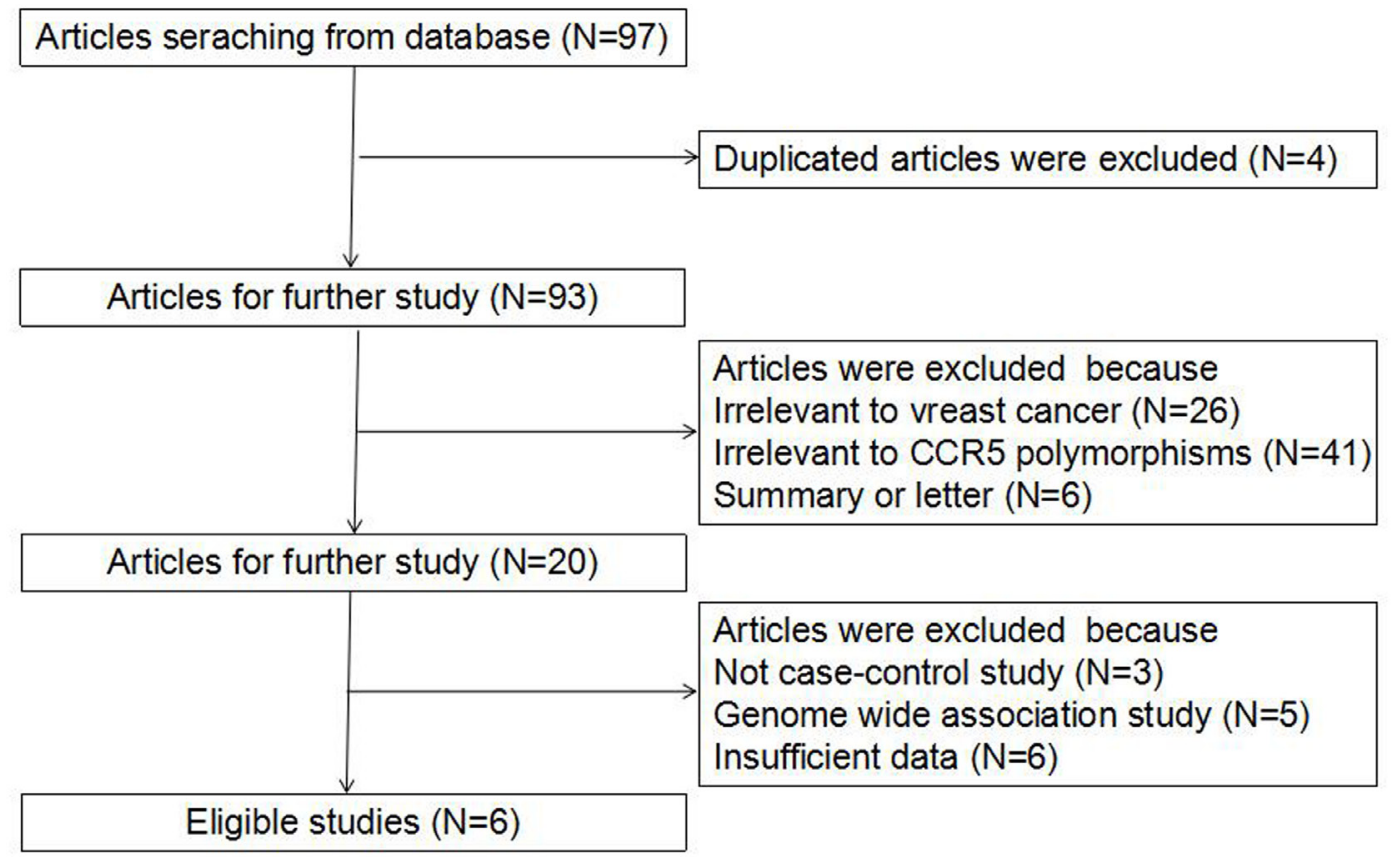

Figure 1: Flow diagram for the process of literature selection. 
Table 1: Principal information of included studies in the meta-analysis

\begin{tabular}{|c|c|c|c|c|c|c|c|c|c|}
\hline \multirow{2}{*}{ First author } & \multirow{2}{*}{ Year } & \multirow{2}{*}{ Country } & \multirow{2}{*}{ Ethnicity } & \multirow{2}{*}{$\begin{array}{l}\text { Control } \\
\text { source }\end{array}$} & \multirow{2}{*}{$\begin{array}{l}\text { Genotyping } \\
\text { method }\end{array}$} & \multicolumn{4}{|c|}{$\begin{array}{l}\text { Genotype and allele distribution } \\
\text { (Case/Control) }\end{array}$} \\
\hline & & & & & & WT/WT & $\begin{array}{l}\mathrm{WT} / \\
\Delta 32\end{array}$ & WT & $\Delta 32$ \\
\hline Aoki & 2009 & Brazil & Caucasian & population & PCR & $67 / 77$ & $5 / 12$ & $139 / 166$ & $5 / 14$ \\
\hline Zafiropoulos & 2004 & Greece & Caucasian & population & PCR & $238 / 196$ & $26 / 14$ & $502 / 406$ & $26 / 14$ \\
\hline Degerli & 2005 & Turkey & Caucasian & hospital & PCR & $36 / 254$ & $3 / 13$ & $75 / 521$ & $3 / 13$ \\
\hline $\begin{array}{l}\text { Eskandari- } \\
\text { Nasab }\end{array}$ & 2014 & Iran & Asian & population & PCR & $231 / 196$ & $5 / 7$ & $467 / 399$ & $5 / 7$ \\
\hline Guleria & 2012 & India & Asian & population & PCR & $76 / 80$ & $4 / 0$ & $156 / 160$ & $4 / 0$ \\
\hline Banin-Hirata & 2015 & Brazil & Brazilian & population & PCR & $107 / 167$ & $11 / 12$ & $225 / 346$ & $11 / 14$ \\
\hline
\end{tabular}

Notes: WT/WT, wild-type homozygous genotype; WT/ $\Delta 32$, heterozygous genotype; WT, wild-type allele; $\Delta 32$, mutated allele; PCR, polymerase chain reaction.

Table 2: $C C R 5 \Delta 32$ polymorphism and the susceptibility to breast cancer

\begin{tabular}{lccccc}
\hline \multirow{2}{*}{ Group } & \multirow{2}{*}{ No. of studies } & \multicolumn{3}{c}{ Odds ratio (95\% confidence interval) / P value for heterogeneity } \\
\cline { 3 - 6 } & 3 & $1.08(0.66,1.78)$ & 0.114 & $1.15(0.69,1.93)$ & 0.181 \\
\hline Caucasian & 2 & $1.14(0.44,2.96)$ & 0.079 & $1.14(0.44,2.98)$ & 0.077 \\
Asian & 1 & $1.21(0.54,2.71)$ & $/$ & $1.43(0.61,3.36)$ & $/$ \\
Brazilian & 5 & $1.08(0.72,1.62)$ & 0.133 & $1.17(0.77,1.78)$ & 0.161 \\
Population & 1 & $1.60(0.45,5.76)$ & $/$ & $1.63(0.44,5.99)$ & $/$ \\
Hospital & 6 & $1.12(0.76,1.65)$ & 0.192 & $1.21(0.81,1.80)$ & 0.235 \\
Total & 6 &
\end{tabular}

Notes: WT/WT, wild-type homozygous genotype; WT/ $\Delta 32$, heterozygous genotype; WT, wild-type allele; $\Delta 32$, mutated allele.

\section{Publication bias examination}

In the investigation of potential publication bias, none of the funnel plots was found to be asymmetrical through visual check (Figure 3), and these conditions were statistically verified by evidence from Egger's test ( $P=0.307)$, which demonstrated that the publication bias was negligible.

\section{DISCUSSION}

In spite the pathogenesis of $\mathrm{BC}$ is not definite, documents demonstrate that various factors participate in the onset of BC [24-26]. Besides, increasing evidences manifest that the genetic backgrounds may decide the individual susceptibility to $\mathrm{BC}$ development.

CCR5 mainly distributed in various immune cells and endothelial cells, and is regarded as the specific surface marker for Th1 cells [27]. After combining with its specific ligands (such as CCL3, CCL4 and CCL5), CCR5 can activate $\mathrm{G}$ protein and ultimately elevate the intracellular concentration of $\mathrm{Ca}^{2+}$ and activate protein kinases $\mathrm{C}$, thus regulating the migration and proliferation of immune cells [28]. The $\Delta 32$ polymorphism, one of the most studied polymorphisms in this gene, refers to the mutation caused by the missing of 32 bases in the gene. The $\Delta 32$ polymorphism in CCR 5 gene may lead to abnormal protein expression. It has been investigated that this polymorphism might participate in the occurrence of various cancers, including BC. In a study performed among a Turkish population, the heterozygote genotype of $\Delta 32$ polymorphism was revealed to be an independent risk factor for breast cancer development [21]. A similar metaanalysis exploring the association between CCR5 $\Delta 32$ polymorphism and various cancer types also suggested a possible impact thereof on BC [29]. However, this association was not suggested by Aoki et al., Zafiropoulos et al., and Banin-Hirata et al. in their studies [18-20]. Considering the small sample sizes in some of them, we performed this meta-analysis for a more reliable conclusion on this relationship.

In this meta-analysis, we statistically synthesized findings from several eligible case-control studies involving the association between CCR5 $\triangle 32$ polymorphism and $\mathrm{BC}$ risk, and found no evidence for significant correlation between them in both the overall 
analysis and subgroup analyses according to ethnicity and control source. As could be known, our conclusions were inconsistent from those of some previous studies. Reasons for the discrepancy may include the following aspects. To begin with, the selection criteria of participants were not the same, so other potential risk factors for BC such as ethnicity and BC family history might statistically differ. Next, the sample size of some studies was relatively smaller, which might weaken the statistical power of final results. Also, in some studies, the $\Delta 32$ polymorphism had interactive effects on $\mathrm{BC}$ together with other genetic variants, which meant that those variants might interfere

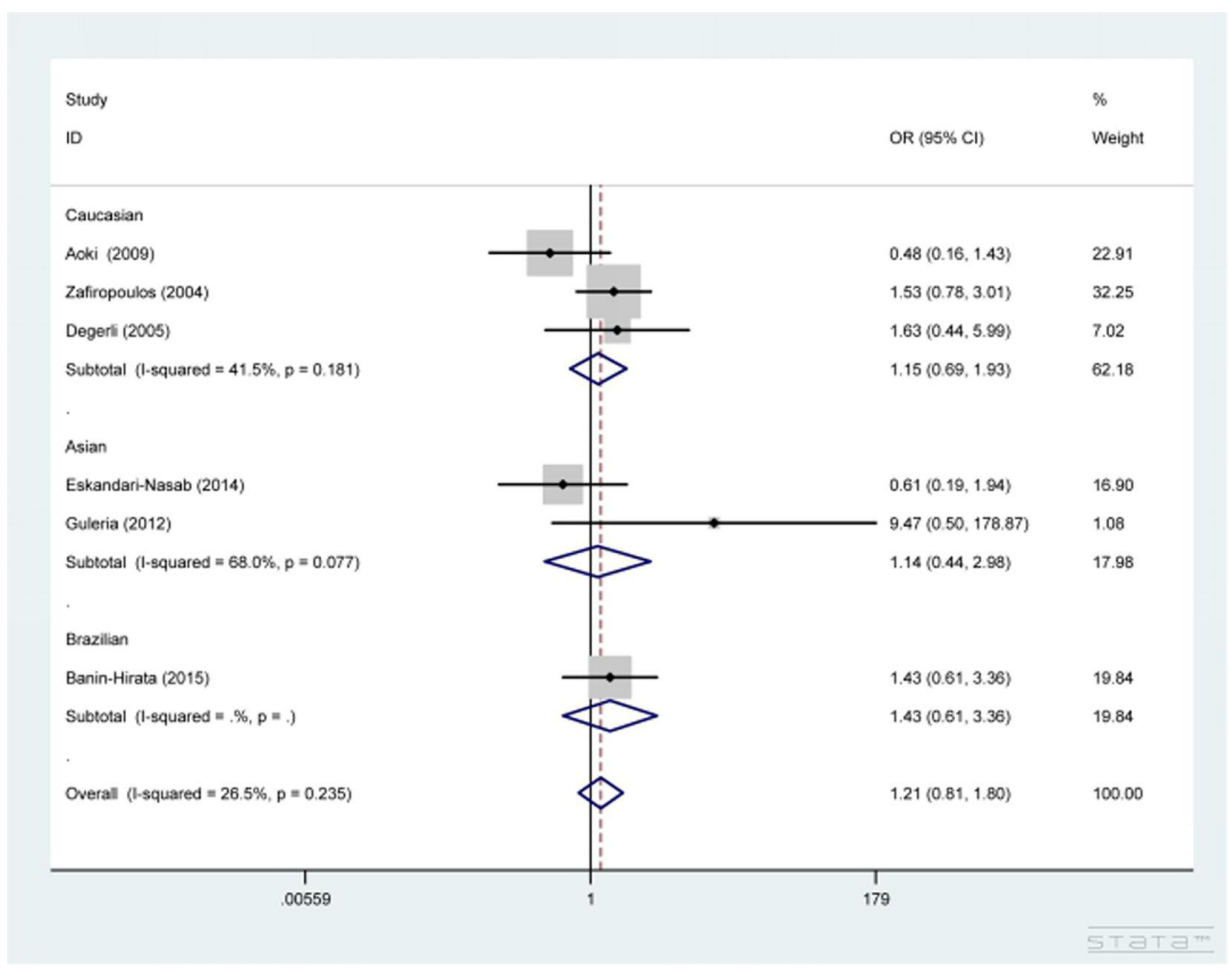

Figure 2: Forest plot for the association between CCR5 $\Delta 32$ polymorphism and the susceptibility to breast cancer under WT/ $\mathbf{\Delta 3 2}$ vs. WT/WT contrast. The squares and horizontal lines correspond to the study-specific OR and 95\% CI. The area of the squares reflects the weight (inverse of the variance). The diamond represents the summary OR and 95\% CI.

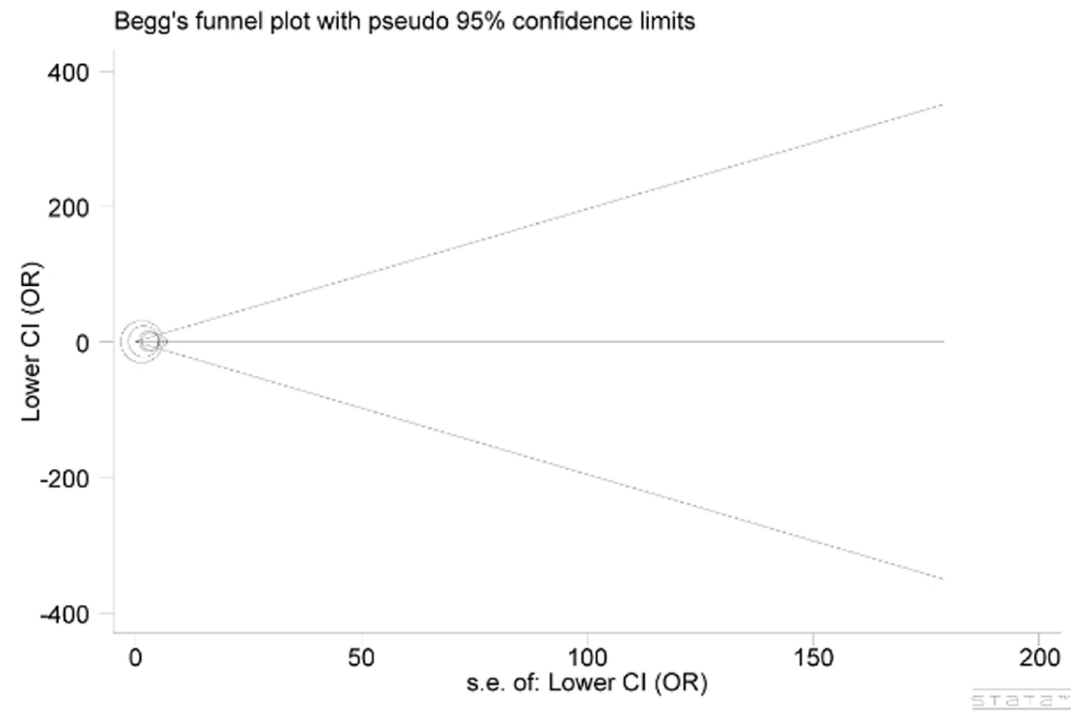

Figure 3: Begg's funnel plot for publication bias. Each point represents a separate study for the indicated association. $\log (\mathrm{OR})$, natural logarithm of OR. Horizontal line, mean effect size. 
with the independent role of $\Delta 32$ polymorphism. This conclusion was contrary to that from a previous metaanalysis by Lee et al. [29], in which a positive relationship of the polymorphism with the risk of $\mathrm{BC}$ was revealed. As for the discrepancies between our findings and their conclusion, they might be explained by some differences between our meta-analysis and their study. For example, our meta-analysis incorporated more studies on BC compared to theirs. Additionally, the participants for BC in their study were all Caucasians while ours enrolled Asian populations as well.

Compared with the above-mentioned studies, our meta-analysis has the advantages of a greater sample size and more comprehensive analyses by dividing the subjects into different subgroups on the basis of ethnicity and source of control. However, some aspects might affect the accuracy of our findings, such as the relatively small number of included studies, the lack of further subgroup analyses based on age, smoking status and other risk factors, as well as the absence of consideration of potential collective effects of our studied polymorphism with other relevant elements on the risk of $\mathrm{BC}$. Therefore, the outcomes from the present study still need to be applied with prudence.

In conclusion, our findings do not support the assumption that CCR5 $\triangle 32$ polymorphism has independent influences on individual susceptibility to BC. Nevertheless, these results are required to be further verified by studies with larger sample size in future.

\section{MATERIALS AND METHODS}

\section{Literature searching}

A systemic search was conducted in the databases of PubMed, EMBASE, Google Scholar Web and CNKI for all relevant papers published in English or Chinese language, using the combination of the following keywords: "chemokine C-C motif receptor 5" or "CCR5" or "CD195", "breast cancer" or "breast carcinoma" or "mammary cancer", and "polymorphism" or "mutation" or "variant". To maximize the number of included studies, the references of relevant articles were all manually checked to supplement the yield of database searching.

\section{Inclusion and exclusion criteria}

Every included report must conform to the following criteria: (1) with a case-control design; (2) assessing the relationship between $C C R 5 \Delta 32$ polymorphism and BC risk; (3) using validated genotyping method; (4) stating sufficient information on genotype and/or allele distribution both in case and control groups; and (5) focusing on human beings. Papers failing to meet any one of the above standards were eliminated from the present meta-analysis. Besides, excluded publications also contained letters, commentaries, case reports and review articles. If more than one article included the same group of participants, the one with the largest sample size or published most recently was selected.

\section{Data extraction}

Two investigators independently extracted primary information from all eligible studies using the same data table. Information to be recorded contained the following aspects: first author's name, publication year, original country, ethnic descent, number of cases and controls, control source, genotyping method, frequencies of genotypes and/or alleles in cases and controls, and $P$ value for Hardy-Weinberg equilibrium (HWE). Crosscheck of each item extracted from the eligible studies was completed by these two investigators to guarantee the accuracy of the data. If any discrepancies occurred, they would be settled through discussion between the two investigators until reaching a consensus.

\section{Statistical analysis}

The intensity of the relationship of CCR5 $\triangle 32$ polymorphism with $\mathrm{BC}$ susceptibility was appraised through calculating odds ratios (ORs) with the corresponding 95\% confidence intervals (95\% CIs). Between-study heterogeneity was examined with chisquare-based $\mathrm{Q}$ test. When $P$ value less than 0.05 represented the existence of significant heterogeneity, the random-effects model was selected to calculate the overall ORs; otherwise, fixed-effects model has been selected. Sensitivity analysis was completed through removing each of included studies in turn and re-calculating pooled ORs to observe the impact on whole results. Additionally, Begg's funnel plot and Egger's regression test were both applied to inspect potential publication bias across selected studies. All data syntheses in the present metaanalysis were conducted with STATA 12.0 software (Stata Corporation, College Station, TX, USA).

\section{CONFLICTS OF INTEREST}

The authors declare no conflicts of interest.

\section{FUNDING}

This work was supported by grants from Application Development Foundation of Chongqing (cstc2014yykfa110036).

\section{REFERENCES}

1. Liang $\mathrm{H}$, Yan Y, Li T, Li R, Li M, Li S, Qin X. Methylenetetrahydrofolate reductase polymorphisms and breast cancer risk in Chinese population: a meta-analysis of 22 case-control studies. Tumour Biol. 2014; 35:1695-1701. 
2. Kumar P, Yadav U, Rai V. Methylenetetrahydrofolate reductase gene $\mathrm{C} 677 \mathrm{~T}$ polymorphism and breast cancer risk: evidence for genetic susceptibility. Meta Gene. 2015; 6:72-84

3. Autier P, Boniol M, La Vecchia C, Vatten L, Gavin A, Hery C, Heanue M. Disparities in breast cancer mortality trends between 30 European countries: retrospective trend analysis of WHO mortality database. BMJ. 2010; 341:c3620.

4. Kohler BA, Sherman RL, Howlader N, Jemal A, Ryerson AB, Henry KA, Boscoe FP, Cronin KA, Lake A, Noone AM, Henley SJ, Eheman CR, Anderson RN, Penberthy L. Annual report to the nation on the status of cancer, 19752011, featuring incidence of breast cancer subtypes by race/ethnicity, poverty, and state. J Natl Cancer Inst. 2015; 107:djv048.

5. DeSantis C, Ma J, Bryan L, Jemal A. Breast cancer statistics, 2013. CA Cancer J Clin. 2014; 64:52-62.

6. Siegel RL, Miller KD, Jemal A. Cancer statistics, 2015. CA Cancer J Clin. 2015; 65:5-29.

7. Long N, Moore MA, Chen W, Gao CM, Lai MS, Mizoue T, Oyunchimeg D, Park S, Shin HR, Tajima K, Yoo KY, Sobue T. Cancer epidemiology and control in north-East Asia - past, present and future. Asian Pac J Cancer Prev. 2010; 11:107-148.

8. Chiranjeevi P, Spurthi KM, Rani NS, Kumar GR, Aiyengar TM, Saraswati M, Srilatha G, Kumar GK, Sinha S, Kumari CS, Reddy BN, Vishnupriya S, Rani HS. Gelatinase B $(-1562 \mathrm{C} / \mathrm{T})$ polymorphism in tumor progression and invasion of breast cancer. Tumour Biol. 2014; 35:1351-1356.

9. Bayram S, Sumbul AT, Dadas E. A functional HOTAIR rs12826786 C>T polymorphism is associated with breast cancer susceptibility and poor clinicopathological characteristics in a Turkish population: a hospital-based case-control study. Tumour Biol. 2016; 37:5577-5584.

10. Smith SG, Sestak I, Forster A, Partridge A, Side L, Wolf MS, Horne R, Wardle J, Cuzick J. Factors affecting uptake and adherence to breast cancer chemoprevention: a systematic review and meta-analysis. Ann Oncol. 2016; 27:575-590.

11. Mavaddat N, Antoniou AC, Easton DF, Garcia-Closas M. Genetic susceptibility to breast cancer. Mol Oncol. 2010; 4:174-191.

12. Mantovani A, Savino B, Locati M, Zammataro L, Allavena P, Bonecchi R. The chemokine system in cancer biology and therapy. Cytokine Growth Factor Rev. 2010; 21:27-39.

13. Ying H, Wang J, Gao X. CCL5-403, CCR5-59029, and Delta32 polymorphisms and cancer risk: a metaanalysis based on 20,625 subjects. Tumour Biol. 2014; 35:5895-5904.

14. Zambra FM, Biolchi V, Brum IS, Chies JA. CCR2 and CCR5 genes polymorphisms in benign prostatic hyperplasia and prostate cancer. Hum Immunol. 2013; 74:1003-1008.
15. de Oliveira CE, Amarante MK, Perim Ade L, Ozawa PM, Hiroki C, Freire Vitiello GA, Losi Guembarovski R, Watanabe MA. Absence of association between CCR5 rs333 polymorphism and childhood acute lymphoblastic leukemia. Adv Hematol. 2014; 2014:924030.

16. Tanyel CR, Cincin ZB, Gokcen-Rohlig B, Bektas-Kayhan K, Unur M, Cakmakoglu B. Effects of genetic variants of CCR5 chemokine receptors on oral squamous cell carcinoma. Genet Mol Res. 2013; 12:5714-5720.

17. Gurdol F, Yurdum LM, Ozturk U, Isbilen E, Cakmakoglu B. Association of the CC chemokine receptor 5 (CCR5) polymorphisms with preeclampsia in Turkish women. Arch Gynecol Obstet. 2012; 286:51-54.

18. Aoki MN, da Silva do Amaral Herrera AC, Amarante MK, do Val Carneiro JL, Fungaro MH, Watanabe MA. CCR5 and p53 codon 72 gene polymorphisms: implications in breast cancer development. Int J Mol Med. 2009; 23:429-435.

19. Zafiropoulos A, Crikas N, Passam AM, Spandidos DA. Significant involvement of CCR2-64I and CXCL12-3a in the development of sporadic breast cancer. J Med Genet. 2004; 41:e59.

20. Banin-Hirata BK, Losi-Guembarovski R, Oda JM, de Oliveira CE, Campos CZ, Mazzuco TL, Borelli SD, Ceribelli JR, Watanabe MA. CCR2-V64I genetic polymorphism: a possible involvement in HER2+ breast cancer. Clin Exp Med. 2016; 16:139-145.

21. Degerli N, Yilmaz E, Bardakci F. The delta32 allele distribution of the CCR5 gene and its relationship with certain cancers in a Turkish population. Clin Biochem. 2005; 38:248-252.

22. Eskandari-Nasab E, Hashemi M, Ebrahimi M, Amininia S, Bahari G, Mashhadi MA, Taheri M. Evaluation of CCL5 -403 G>A and CCR5 Delta32 gene polymorphisms in patients with breast cancer. Cancer Biomark. 2014; 14:343-351.

23. Guleria K, Sharma S, Manjari M, Uppal MS, Singh NR, Sambyal V. p.R72P, PIN3 Ins 16bp polymorphisms of TP53 and CCR5?32 in north Indian breast cancer patients. Asian Pac J Cancer Prev. 2012; 13:3305-3311.

24. Patel A, Roston A, Uy A, Radeke E, Keith L, Zaren HA. Reproductive health and endocrine disruption in women with breast cancer: a pilot study. Support Care Cancer. $2015 ; 23: 411-418$.

25. Kaminska M, Ciszewski T, Lopacka-Szatan K, Miotla P, Staroslawska E. Breast cancer risk factors. Prz Menopauzalny. 2015; 14:196-202.

26. Memon ZA, Kanwal N, Sami M, Larik PA, Farooq MZ. Risk of breast cancer among young women and importance of early screening. Asian Pac J Cancer Prev. 2015; 16:7485-7489.

27. Kim SM, Kim BY, Lee SA, Eo SK, Yun Y, Kim CD, Kim K. 27-Hydroxycholesterol and 7alpha-hydroxycholesterol trigger a sequence of events leading to migration of 
CCR5-expressing Th1 lymphocytes. Toxicol Appl Pharmacol. 2014; 274:462-470.

28. Valaperti A, Nishii M, Liu Y, Naito K, Chan M, Zhang L, Skurk C, Schultheiss HP, Wells GA, Eriksson U, Liu PP. Innate immune interleukin-1 receptor-associated kinase 4 exacerbates viral myocarditis by reducing CCR5(+)
$\mathrm{CD} 11 \mathrm{~b}(+)$ monocyte migration and impairing interferon production. Circulation. 2013; 128:1542-1554.

29. Lee YH, Song GG. Association between chemokine receptor 5 delta32 polymorphism and susceptibility to cancer: a meta-analysis. J Recept Signal Transduct Res. 2015; 35:509-515. 